\title{
State of the Art of Machine Learning-Enabled Clinical Decision Support in Intensive Care Units: Literature Review
}

Na Hong ${ }^{1}$, PhD; Chun Liu ${ }^{1}$, PhD; Jianwei Gao ${ }^{1}$, PhD; Lin Han ${ }^{1}$, MSc, MD; Fengxiang Chang ${ }^{1}$, PhD; Mengchun Gong ${ }^{1}, \mathrm{MD}, \mathrm{PhD}$; Longxiang $\mathrm{Su}^{2}, \mathrm{MD}, \mathrm{PhD}$

${ }^{1}$ Digital Health China Technologies Ltd Co, Beijing, China

${ }^{2}$ Department of Critical Care Medicine, State Key Laboratory of Complex Severe and Rare Diseases, Peking Union Medical College Hospital, Chinese Academy of Medical Science and Peking Union Medical College, Beijing, China

\section{Corresponding Author:}

Longxiang $\mathrm{Su}, \mathrm{MD}, \mathrm{PhD}$

Department of Critical Care Medicine

State Key Laboratory of Complex Severe and Rare Diseases, Peking Union Medical College Hospital

Chinese Academy of Medical Science and Peking Union Medical College

No.1 Shuaifuyuan Wangfujing Dongcheng District

Beijing

China

Phone: 861069152308

Email: sulongxiang@vip.163.com

\begin{abstract}
Background: Modern clinical care in intensive care units is full of rich data, and machine learning has great potential to support clinical decision-making. The development of intelligent machine learning-based clinical decision support systems is facing great opportunities and challenges. Clinical decision support systems may directly help clinicians accurately diagnose, predict outcomes, identify risk events, or decide treatments at the point of care.
\end{abstract}

Objective: We aimed to review the research and application of machine learning-enabled clinical decision support studies in intensive care units to help clinicians, researchers, developers, and policy makers better understand the advantages and limitations of machine learning-supported diagnosis, outcome prediction, risk event identification, and intensive care unit point-of-care recommendations.

Methods: We searched papers published in the PubMed database between January 1980 and October 2020. We defined selection criteria to identify papers that focused on machine learning-enabled clinical decision support studies in intensive care units and reviewed the following aspects: research topics, study cohorts, machine learning models, analysis variables, and evaluation metrics.

Results: A total of 643 papers were collected, and using our selection criteria, 97 studies were found. Studies were categorized into 4 topics - monitoring, detection, and diagnosis (13/97, 13.4\%), early identification of clinical events (32/97, 33.0\%), outcome prediction and prognosis assessment $(46 / 97,47.6 \%)$, and treatment decision $(6 / 97,6.2 \%)$. Of the 97 papers, $82(84.5 \%)$ studies used data from adult patients, $9(9.3 \%)$ studies used data from pediatric patients, and $6(6.2 \%)$ studies used data from neonates. We found that $65(67.0 \%)$ studies used data from a single center, and $32(33.0 \%)$ studies used a multicenter data set; $88(90.7 \%)$ studies used supervised learning, $3(3.1 \%)$ studies used unsupervised learning, and $6(6.2 \%)$ studies used reinforcement learning. Clinical variable categories, starting with the most frequently used, were demographic $(n=74)$, laboratory values $(n=59)$, vital signs $(n=55)$, scores $(n=48)$, ventilation parameters $(n=43)$, comorbidities $(n=27)$, medications $(n=18)$, outcome $(n=14)$, fluid balance $(n=13)$, nonmedicine therapy $(n=10)$, symptoms $(n=7)$, and medical history $(n=4)$. The most frequently adopted evaluation metrics for clinical data modeling studies included area under the receiver operating characteristic curve $(n=61)$, sensitivity $(n=51)$, specificity $(n=41)$, accuracy $(n=29)$, and positive predictive value $(n=23)$.

Conclusions: Early identification of clinical and outcome prediction and prognosis assessment contributed to approximately $80 \%$ of studies included in this review. Using new algorithms to solve intensive care unit clinical problems by developing reinforcement learning, active learning, and time-series analysis methods for clinical decision support will be greater development prospects in the future. 
(JMIR Med Inform 2022;10(3):e28781) doi: 10.2196/28781

\section{KEYWORDS}

machine learning; intensive care units; clinical decision support; prediction model; artificial intelligence; electronic health records

\section{Introduction}

With the popularization of electronic health records, medical equipment, and the improvement of detection methods, patient data are generated in large amounts every day in intensive care units. In traditional clinical data analysis, models and tools can only make use of a limited number of variables in clean and well-organized data. Machine learning has enabled clinical decision support research and applications to generate actionable insights, by utilizing large amounts of intensive care unit patient data, that are useful in many clinical scenarios.

Machine learning, sometimes called the data-driven method, uses statistical analysis models and computational technologies, allowing computer systems to learn from patient data and discover unknown clinical situations. Supervised learning, unsupervised learning, and reinforcement learning are the 3 main types of machine learning [1] used to predict or guide the treatment of patients who are critically ill.

In supervised machine learning tasks, a function maps an input to an output based on example input-output pairs. Functions are inferred from labeled training data. Classification and regression methods, which include but are not limited to linear regression, logistic regression, decision tree, random forest, and support vector machine, are common supervised learning methods.

In unsupervised machine learning tasks, patterns are learned from untagged data. Models are designed to identify or partition large data sets into subsections or clusters that share similar characteristics. In intensive care unit-related tasks, unsupervised learning enables the discovery of latent structures or patient subgroups in specific cohorts [2]. Commonly used unsupervised learning models include clustering, auto-encoding, and principal component analysis.

Reinforcement learning is concerned with how intelligent agents ought to take actions in an environment to maximize the notion of cumulative rewards. The environment is typically defined by a discrete-time stochastic control process called the Markov decision process. In an intensive care unit, clinicians often need to determine treatment plans and make clinical decisions. Reinforcement learning models have great potential for solving these types of problems by providing targeted treatment plans for each patient or patient status and assisting clinicians in making efficient decisions [3-8].

Although there are still challenges when data from multiple sources must be combined, and the performance and ability of machine learning is limited by the volume and quality of data, a number of clinical decision support studies $[9,10]$ have demonstrated the ability to use sophisticated machine learning models to solve certain intensive care unit-related tasks, and their performance has been shown to be comparable with human abilities, and for certain tasks, even it potentially exceeds human abilities [7,11].

We sought to focus on machine learning research and applications adapted to clinical decision support in intensive care units, which may directly help clinicians diagnoses accurately, predict outcomes, identify risk events, or decide treatments at the intensive care unit point of care.

\section{Methods}

\section{Search Strategy}

We searched for papers in the PubMed database that had been published prior to October 2020 using a query combination of MeSH terms ("intensive care unit," "critical care," "machine learning," "artificial intelligence," "decision support systems, clinical") and keywords in the title or abstract keywords related to machine learning ("machine learning," "artificial intelligence," "prediction model," "predictive model," "predictive modeling," "artificial learning," "predictive analysis," "machine intelligence," "data driven," "data-driven," "statistical learning," "neural network," "deep learning," "reinforcement learning," "time series," "time-series," "algorithm"), decision-making ("clinical decision support system," "medical decision," "decision tool," "support tool," "clinical decision," "physician decision," "clinician decision," "decision algorithm," "CDSS," "CDS," "clinical management," "decision making," "decision-making"), and intensive care units ("intensive care," "ICU," "critical care," "intensive care unit").

\section{Selection Criteria}

We included English-language papers that reported studies (both prospective and retrospective studies) on clinical decision support, with machine learning methods that targeted a specific clinical scenario of intensive care units. We excluded papers that were systematic reviews and meta-analyses, studies of clinical decision support system implementations or clinical decision support system usability evaluations, studies that described rule-based clinical decision support system, studies that used data that were not from patients in intensive care units (eg, studies for intensive care unit admission prediction but using patient data from other departments, such as emergency or surgery departments), studies with outcomes irrelevant to regular intensive care unit clinical care (eg, studies about estimation of caffeine regimens), and studies that did not use machine learning methods (eg, studies using clinical scores or statistical analysis on small samples).

\section{Data Analysis}

We extracted the following information from selected papers for content analysis: study cohort, machine learning models, analysis variables, evaluation methods, and research topics. 


\section{Study Cohort}

In general, the greater the number of data sets to which a machine learning model is applied, the stronger its generalization capabilities. Therefore, we investigated the inclusion cohorts and distribution centers of each study and classified these studies into single-site or multisite studies accordingly. We also classified studies by $c$, the sample size of studies: $c<500$, $500<c<2000,2000<c<5000,5000<c<10,000,10,000<c<50,000$, and $c>50,000$.

\section{Machine Learning Models}

The model methods or algorithms used in each paper were reviewed for analysis, and model methods were categorized as supervised learning, unsupervised learning, or reinforcement learning.

We reviewed variables or features used for modeling in each study. According to routine intensive care unit practices, we classified these variables into 12 groups: demographic variables, vital signs, symptoms, laboratory values, ventilation parameters, medications, nonmedicine therapy, comorbidities, fluid balance, scores, medical history, and outcome. Given the wide range of variable expressions in papers, such as formal medical terms, abbreviations, acronyms, and capitalizations, variable name normalization was implemented using text processing and manual annotation methods. As some studies used self-defined features or derived data for their special study purpose, variables used in only 1 study were excluded.

\section{Evaluation Methods}

To determine the applicability and potential impact of various machine learning models for clinicians and patients (ie, in applications), model evaluation methods are important components of model development. We reviewed evaluation metrics used for measuring model performance.

\section{Research Topics}

In addition to overall quantitative analysis, which included all studies, selected papers were divided into 4 topics for detailed analysis: detection and monitoring for diagnosis, early identification of clinical events, patient outcome prediction, and treatment decisions.

\section{Results}

\section{General}

A total of 643 papers were found. The number of machine learning-enabled intensive care unit clinical decision support system research papers published in the PubMed database has been continuously increasing between January 1980 and October 2020 (Figure 1).

Among the 643 papers identified and assessed for eligibility, 14 non-English language papers, 55 clinical decision support system implementations and clinical decision support system usability evaluations, 114 reviews and meta-analyses, 35 expert system clinical decision support system studies, 68 studies not about intensive care unit clinical questions, 76 studies using patient data from other clinical departments or with outcomes irrelevant to regular intensive care unit clinical care, 107 studies that used methods other than machine learning, and 77 studies for which full-text papers were unavailable were excluded (Figure 2); therefore, 97 papers remained (Table 1).

Most studies used data from adult patients $(n=82,84.5 \%)$; however, 8 studies used data from pediatric patients $(8.2 \%)$ and 7 studies used data from neonates (7.2\%). Two-thirds of the studies $(65 / 97,67.0 \%)$ were developed from single-center data sets, and $32(33.0 \%)$ were developed from a multicenter data set; cohort sizes also varied ( $c<500: 35 / 97,36 \%$; $500<c<2000$ : 19/97, 20\%; 2000<c<5000: 12/97, 12\%; 5000<c<10000: 10/97, 10\%; 10000<c<50000: 16/97, 16\%; $c>50,000: 7 / 97,7 \%)$.

The vast majority of studies used supervised learning (88/97, $91 \%)$, and only a few used unsupervised learning $(3 / 97,3 \%)$ or reinforcement learning $(6 / 97,6 \%)$. In total, 849 variables for model analysis were extracted. The most frequent variable categories are shown in Table 1, and the top 20 most frequently used variables are shown in Figure 3.

Most studies used more than 1 evaluation metric. The most frequently used were area under receiver operating characteristic curve $(n=57)$, sensitivity $(n=37)$, specificity $(n=31)$, and accuracy $(n=24)$. 
Figure 1. Growth in number of publications.

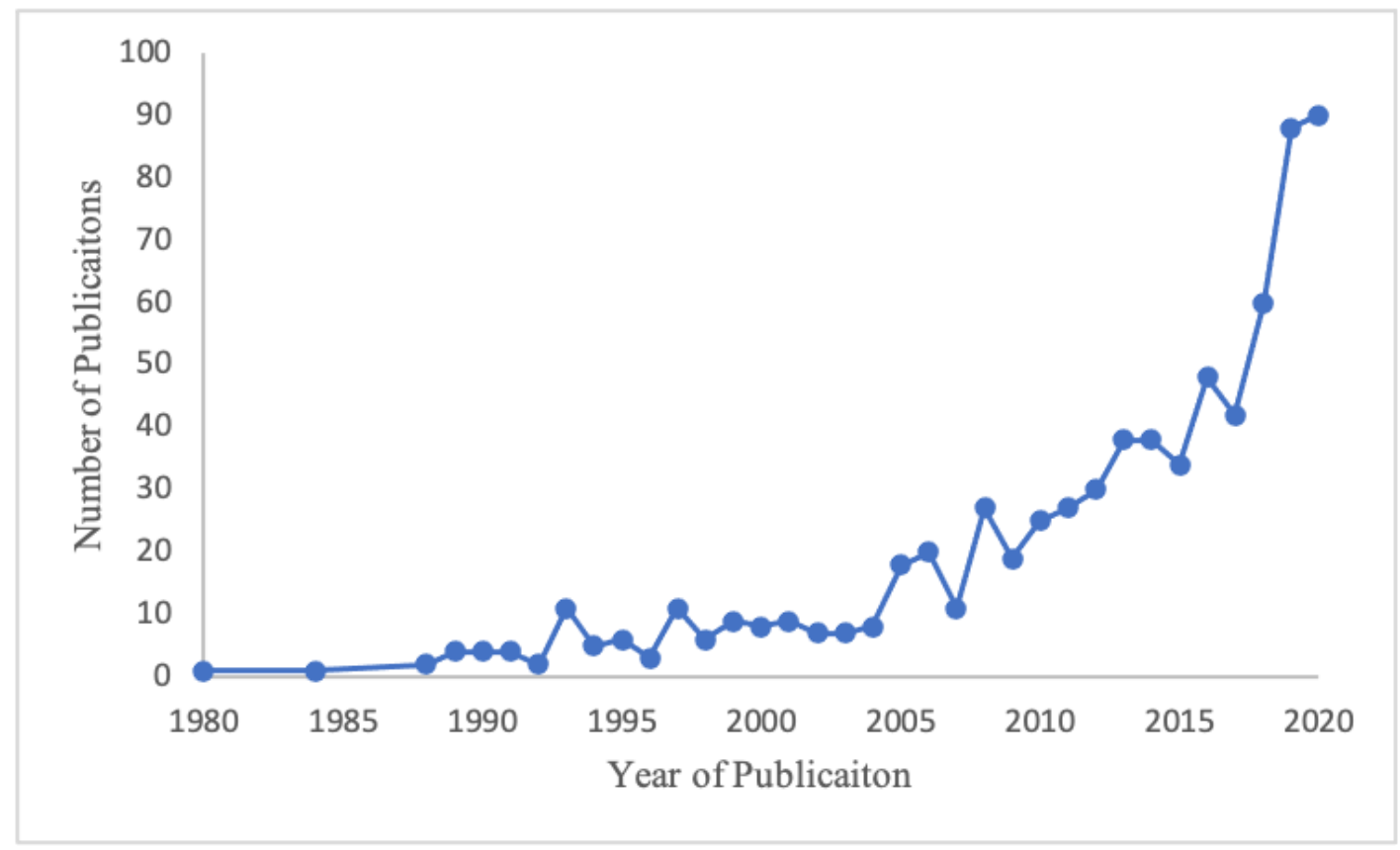

Figure 2. Article review process. CDSS: clinical decision support system; ICU: intensive care unit.

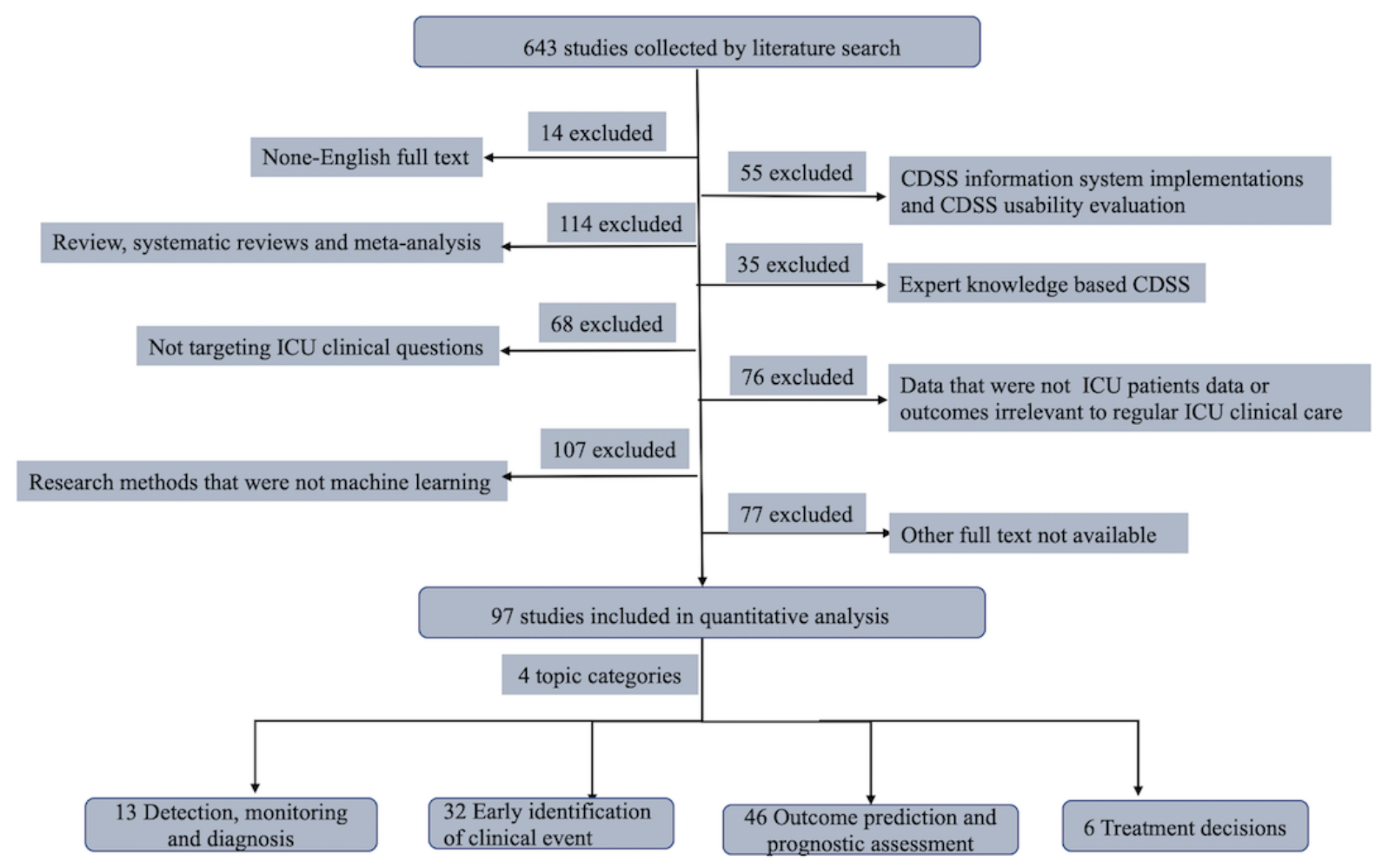


Table 1. General characteristics of the selected studies.

\begin{tabular}{ll}
\hline Characteristic & Value $(n=97), n$
\end{tabular}

Types of decision support

$\begin{array}{ll}\text { Detection, monitoring, and diagnosis } & 13\end{array}$

Early identification of clinical events $\quad 32$

Outcome prediction and prognostic assessment $\quad 46$

$\begin{array}{lc}\text { Treatment decisions } & 6\end{array}$

Population

$\begin{array}{ll}\text { Adult } & 82\end{array}$

$\begin{array}{lc}\text { Pediatric patients } & 8\end{array}$

$\begin{array}{ll}\text { Neonates } & 7\end{array}$

\section{Medical setting}

Single-center

Multicenter

Type of machine learning

$\begin{array}{lr}\text { Supervised learning } & 88\end{array}$

Unsupervised learning 3

Reinforcement learning 6

\section{Type of variables}

$\begin{array}{ll}\text { Demographic variables } & 74\end{array}$

Laboratory values $\quad 59$

Vital signs $\quad 55$

$\begin{array}{lr}\text { Scores } & 48\end{array}$

Ventilation parameters $\quad 43$

$\begin{array}{ll}\text { Comorbidities } & 27\end{array}$

Medications 18

$\begin{array}{ll}\text { Outcome } & 14\end{array}$

Fluid balance $\quad 13$

$\begin{array}{ll}\text { Nonmedicine therapy } & 10\end{array}$

$\begin{array}{ll}\text { Symptoms } & 7\end{array}$

Medical history 4

Type of evaluation method, $\mathbf{n}^{\text {a }}$

$\begin{array}{ll}\text { Area under the receiver operating characteristic curve } & 57\end{array}$

$\begin{array}{ll}\text { Sensitivity } & 37\end{array}$

Specificity 31

$\begin{array}{ll}\text { Accuracy } & 24\end{array}$

Positive predictive value $\quad 11$

${ }^{\mathrm{a}}$ More than 1 variable type could be used in each study. 
Figure 3. Top 20 most frequently used variables. DBP: diastolic blood pressure; FiO2: fractional inspired oxygen; GCS: Glasgow Coma Scale; HR: heart rate; MBP: mean blood pressure; MV: mechanical ventilation; PaO2-partial pressure of oxygen; RR: respiratory rate; SBP: systolic blood pressure; SCR: creatine; SpO2: peripheral capillary oxygen saturation; WBC: white blood cell count.

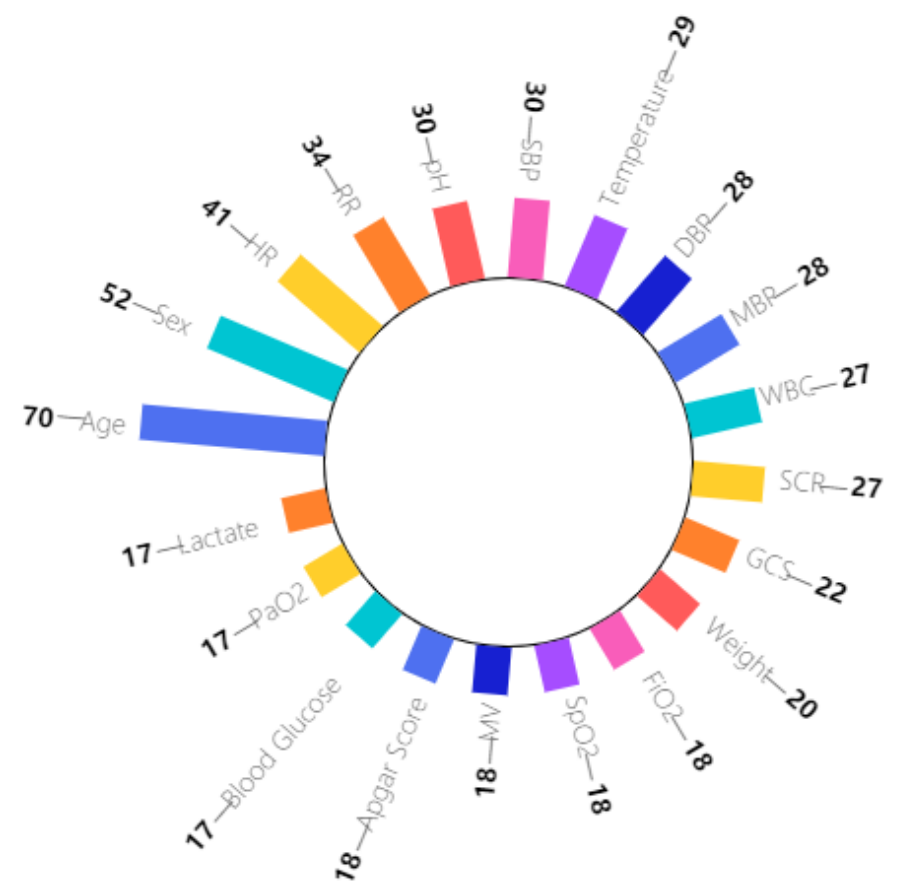

\section{Monitoring, Detection, and Diagnosis}

\section{Overview}

Among 13 studies, $4(30.8 \%)$ studies [12-15] focused on monitoring or detection of physiological indicators, 3 studies (23.1\%) [16-18] focused on the of mechanical ventilation abnormalities (in particular, patient-ventilator asynchrony), 4 studies (30.8\%) [19-22] used electroencephalography (EEG) to diagnose brain diseases, and 2 studies (15.4\%) [11,23] studies focused on infections. Variables used included demographic variables $(n=5)$, vital signs $(n=6)$, laboratory values $(n=5)$, ventilation parameters $(n=5)$, comorbidities $(n=1)$, and outcome $(\mathrm{n}=1)$.

Most data were obtained from a single center $(11 / 13,84.6 \%)$, and only 2 studies $(2 / 13,15.4 \%)$ used multicenter data sets. Some studies $(3 / 13,23.1 \%)$ used data from public databases, such as the MIMIC database, the public NIH Chest-XRay14, and PLCO data sets (Multimedia Appendix 1).

The top 3 models used were neural network $(n=4)$, tree $(n=3)$, and random forest $(n=3)$ models. Support vector machine models were used twice $(n=2)$. Other models, such as logistic regression, and linear regression were only used in 1 study each.

Model performance was mainly evaluated with sensitivity $(n=7)$, specificity $(n=8)$, area under the receiver operating characteristic curve $(n=3)$, and accuracy $(n=3)$, whereas other evaluation methods such as equal error rates, F1 score, recall, and $\kappa$ coefficients were each used only once.

\section{Monitoring of Physiological Indicators}

Quinn et al [13] provided a general model for inferring hidden factors from clinical data and was successfully applied to the major task of monitoring premature infants in the intensive care unit. Eshelman et al [12] described an algorithm consisting of a set of rules for identifying intensive care unit patients who may become hemodynamically unstable. Taking into account the individual differences of intensive care unit patients, Zhang and Szolovits [15] developed an algorithm based on personalized vital signs data to improve the accuracy of alarms. Charbonnier [14] extracted online temporal episodes from the high-frequency physiological parameters of intensive care unit patients to visually support signal interpretation.

\section{Mechanical Ventilation}

Mechanical ventilation is widely used in intensive care units, during which a series of parameters need to be monitored. Kwok et al [16] established a nonlinear adaptive neuro-fuzzy inference system model for fractional inspired oxygen estimation, which reduced the need for invasive inspections. Two groups of researchers discussed the problem of patient-ventilator asynchrony, and developed a classifier based on machine learning to detect abnormal waveforms $[17,18]$.

\section{Electroencephalography Monitoring}

EEG monitoring plays an important role in the detection of brain function and the diagnosis of brain disease. Koolen et al [19] developed a method for the automated classification of neonatal sleep states via EEG. Golmohammadi et al [21] presented a system that can achieve high-performance classification of EEG events that might correlate with epilepsy, metabolic encephalopathy, cerebral hypoxia, and ischemia. Farzaneh et al [20] developed a machine learning framework to automatically segment and assess the severity of patients with subdural hematoma during traumatic brain injuries [20].

\section{Diagnosis of Infection}

Infections are an important clinical issue in intensive care. Sepsis is a common and serious condition in the intensive care unit that results from an overreaction to infection that damages 
tissues and organs and can lead to complications, making it one of the leading causes of hospital-related deaths [24]. A high-performance algorithm, InSight, was demonstrated to be superior to the commonly used Modified Early Warning Score, Simplified Acute Physiology Score, and Systemic Inflammatory Response Syndrome score for the diagnosis of patients with alcohol use disorder combined with sepsis shock [23]. In addition, it is still challenging to explain lung opacity in radiography of the supine chest of patients with lung infection in the intensive care unit-Rueckel et al [11] evaluated a prototype artificial intelligence algorithm that could classify underlying lung opacity, which might suggest a diagnosis pneumonia.

\section{Early Identification or Prediction of Clinical Events}

\section{Overview}

Clinical event prediction, the use of data from electronic health records to predict the occurrence of certain events or the best time to give treatment, is one of the most important aspects of intensive care unit clinical decision support system. Among 32 clinical event prediction studies, $3(9.4 \%)$ were related to acute kidney injury, $11(34.4 \%)$ were related to infection prediction, $8(25 \%)$ were related to respiratory diseases, and $10(31.3 \%)$ were related to other predictions and evaluations (Multimedia Appendix 1).

In intensive care unit clinical prediction and evaluation studies, up to 87 variables were used in a single paper. Categories of variables, in order of frequency, were laboratory values $(n=25)$, demographic variables $(n=25)$, vital signs $(n=20)$, scores $(n=18)$, ventilation parameters $(n=14)$, fluid balance $(n=8)$, medications $(n=7)$, comorbidities $(n=7)$, outcome $(n=4)$, nonmedicine therapy $(\mathrm{n}=3)$, symptoms $(\mathrm{n}=3)$, and medical history $(\mathrm{n}=1)$.

More than three-quarters of the studies $(25 / 32,78 \%)$ were based on data from a single center, 10 of which were from the freely available public database Medical Information Mart for Intensive Care II or III. Multi-institutional data were used in the other studies $(7 / 32,22 \%)$.

Logistic regression was the most commonly used method (11/32, $34 \%)$, followed by neural networks $(7 / 32,21 \%)$, and random forest $(6,19 \%)$. Support vector machine and decision tree models were each used in $5(15.6 \%)$ studies. Naive Bayes, gradient boosting tree model, extreme gradient boosting, fuzzy model, and Insight each appeared twice (6.3\%).

Sensitivity $(\mathrm{n}=16)$ and area under receiver operating characteristic curve $(n=17)$ were the most commonly used evaluation metrics, followed by specificity $(n=12)$ and accuracy $(n=12)$. The following metrics appeared in fewer than 10 papers: positive predictive value $(n=3), F 1$ score $(n=4)$, and mean absolute error $(n=2)$.

\section{Acute Kidney Injury Prediction}

Early prediction of acute kidney injury has a high value for the long-term survival and quality of life of critically ill patients. Acute kidney injury is often associated with high morbidity and mortality rates in intensive care units. The status of other vital organs, initiation of therapy, patient response, and preexisting comorbidities can all contribute to the development of acute kidney injury [25]. Multiple machine learning methods have been utilized and compared to analyze unstructured clinical records and structured physiological measurements to identify early episodes of acute kidney injury [26]. Soliman et al [25] studied the prognostic impact of early acute kidney injury predicted by data from the first day of admission. One study [27] focused on patients younger than 21 years, who are more likely to recover from disease.

\section{Prediction of Sepsis and Infection}

Early identification and treatment is the key to survival for many sepsis and infection patients [28], but it is difficult for clinicians to predict before it occurs, because it is extremely complex and each patient is different. Early prediction of sepsis using interpretable or uninterpretable machine learning models can help clinicians enhance the accuracy of fever workup [28] to identify and intervene in a timely manner [29-33]. One research aim is to make accurate predictions with as little electronic health record data as possible [34]. Mao et al achieved early prediction of sepsis using only vital signs validated in multiple centers [35]. The prediction of neonatal sepsis has also received substantial research attention in recent years $[36,37]$. One paper [38] focuses on predicting infections caused by a specific microorganism-invasive fungal disease due to Candida species-in intensive care unit patients.

\section{Prediction of Respiratory Disease and Mechanical Ventilation}

Respiratory management in the intensive care unit is an important aspect of critical care and treatment. Early diagnosis of respiratory critical illness has a significant impact on patient prognosis [39]. In addition, maintenance of cardiopulmonary function is required in patients admitted to the intensive care unit due to acute symptoms such as direct trauma, pulmonary infection, heart failure, and sepsis. Machine learning methods can help predict the onset of acute respiratory disease in patients, especially in pediatric patients. Sauthier et al [40] used random forest and logistic regression to predict the time of acute hypoxic respiratory failure in critically ill children with severe influenza. Messinger et al [39] applied a cascaded artificial neural network to design new respiratory scores for early identification of asthma in young children. In addition, early prediction of acute respiratory distress syndrome was studied because of its high morbidity and mortality [41].

Furthermore, ventilator weaning and reintubation after weaning are currently well studied $[42,43]$ in intensive care unit clinical decision support system literature, as well as the effect of drugs on intubation [44]. Moreover, predicting patient oxygen saturation after ventilation [45] and risk factors for failure of mechanical ventilation [46] can help health care professionals respond in a time manner.

\section{Other Predictions and Evaluations}

There were 10 papers that could not be classified; we simply put them into one class separately. There were forecasts for detection and monitoring indicators, such as urine output after fluid administration [47], glucose [48], lactic acid [49], and activated partial thromboplastin time [50]. Lin [47] established a gradient tree-based machine learning model implemented with 
extreme gradient boosting algorithms to predict urine output in sepsis patients after fluid resuscitation to prevent fluid overload-related complications. Pappada et al $[48,49]$ developed a neural network-based model to obtain a complete trajectory of glucose values up to 135 minutes in advance. Mamandipoor et al [49] combined least absolute shrinkage and selection operator regression, random forest, and long short-term memory to predict blood lactate concentration in patients in the intensive care unit. Our previous study also compared multiple machine learning approaches to guide clinical heparin administration by predicting the range of activated partial thromboplastin time values [50]. There were also studies that aimed to reduce unnecessary laboratory tests to streamline the process and reduce the burden on patients [51,52]. Predicted clinical events also included acute traumatic coagulopathy [53], delirium [54], advanced anemia [55], and fluid resuscitation therapy [56].

\section{Outcome Evaluation and Prognostic Assessment}

\section{Overview}

Of 46 papers that used machine learning for outcome evaluation for patients who were critically ill, 11 papers $(23.9 \%)$ predicted overall mortality and survival, 23 papers $(50 \%)$ predicted the outcomes of patients with certain diseases, and 12 papers $(26.1 \%)$ included treatment prognosis, length of stay in the intensive care unit, and other outcome evaluations (Multimedia Appendix 1).

Categories of variables, in order of frequency, were demographic variables $(n=39)$, scores $(n=24)$, laboratory values $(n=23)$, ventilation parameters $(n=20)$, vital signs $(n=18)$, comorbidities $(\mathrm{n}=17)$, medications $(\mathrm{n}=10)$, outcome $(\mathrm{n}=8)$, nonmedicine therapy $(n=7)$, fluid balance $(n=4)$, symptoms $(n=4)$, and medical history $(n=3)$.

Of the 46 outcome prediction studies, 25 (54.3\%) were based on single-center data, 6 of which used data from MIMIC II and III, and the other 21 studies $(45.7 \%)$ made use of multicenter data.

Logistic regression was the most commonly used method (27/46, $59 \%$ ), followed by random forest $(9 / 46,20 \%)$, random forest $(8 / 46,17 \%)$, support vector machine $(7 / 46,15.2 \%)$ and decision tree model $(5 / 46,11 \%)$ studies. The gradient boosting tree model appeared in $4(9 \%)$ studies, and adaptive boosting and linear regression each appeared twice $(4.3 \%)$. Other models that appeared only once are not discussed here.

Area under receiver operating characteristic curve $(n=37)$ was the evaluation metric used most often, followed by sensitivity $(n=14)$, specificity $(n=11)$, positive predictive value $(n=4)$, accuracy $(n=8)$, negative predictive value $(n=6), F 1$ score $(n=2)$, Matthews correlation coefficient $(n=2)$, and Brier score $(n=2)$.

\section{Overall Intensive Care Unit Patient Outcomes}

Typical outcomes were overall mortality [57-62], survival [63], and long-term quality of life [64]. Mortality [65,66] and survival status at 1 year [67] in critically ill patients aged 80 years and older were also studied using machine learning methods.

\section{Outcomes of Patients With Specific Diseases}

Patients with sepsis and infection remain one of the most studied populations in terms of mortality (generally 28 days) [68-72], followed by acute kidney injury [72-75]. There is an increasing trend in outcome prediction studies in critically ill patients with liver disease-acute liver injury [76,77], cirrhosis [77], and advanced liver disease [78] have been studied using machine learning. In patients with severe cancer, 30- [79] and 120-day [80] survival rates were studied retrospectively with logistic regression models.

For cardiac disease, Lee et al [81] used EEG data to predict the outcome of children with cardiac arrest and Murtuza et al [82] found that arterial blood lactate levels can be associated with mortality in children who have undergone cardiac surgery. For brain diseases, the outcomes of patients with subarachnoid hemorrhage [83] and severe traumatic brain injury [84] have been analyzed. Wildman et al [85] predicted the impact of chronic obstructive pulmonary disease and asthma on mortality in critically ill patients. Daly et al [86] used logistic regression to study the relationship between early discharge and mortality with the intention of reducing mortality in this group of intensive care unit patients. Other papers [87-89] examined patient outcomes and factors influencing them after deterioration. Ebadollahi et al [90] predicted the temporal trajectory of physiological data with patient similarity, with the aim to identify universal patterns of disease progression from a large amount of clinical practice data, to establish a generalized computer-aided clinical decision support framework for personalized treatment.

\section{Treatment Prognosis and Intensive Care Unit Stay Time Evaluation}

Evaluating the outcome of certain treatments through machine learning can help medical professionals refine their treatments to achieve better therapeutic effects. Evaluation of outcomes after extubation based on continuous vital sign information and static characteristics of children can help adjust the timing of extubation to reduce mortality [91-93]. Evaluation of prolonged mechanical ventilation [94] and 1-year and 5-year functional survival [95] after cardiac surgery was used to help adjust and optimize postsurgical care practices. Evaluating the length of stay in the intensive care unit $[96,97]$ and the risk of readmission after discharge from the intensive care unit [98] to effectively forecast the trend of the disease could improve treatment and care. In addition, designing and improving critical illness scores to indicate disease severity [99-101] was studied. For example, McRae et al [102] designed a score to quickly determine the severity of COVID-19 and achieved optimistic results in 160 individuals.

\section{Treatment Decisions}

Treatments, clinical determination, and decision-making in the intensive care unit were studied in 6 papers [3-8]. These papers focused on various clinical questions and mainly used a reinforcement learning model. Among them, 4 papers $[3,5,7,8]$ $(67 \%)$ addressed drug dosage, such as optimal vasopressin dose $[3,7]$, heparin dosage [5], and morphine dosage [8]. The other 
2 papers [4,6] $(33 \%)$ studied the timing of mechanical ventilation extubation.

Categories of variables, in order of frequency, were vital signs $(n=6)$, demographic variables $(n=5)$, laboratory values $(n=5)$, ventilation parameters $(n=3)$, medications $(n=4)$, fluid balance $(n=2)$, scores $(n=4)$, and comorbidities $(n=1)$ (Multimedia Appendix 1).

Reinforcement learning models can be divided into conventional reinforcement learning models (that is, wherein the reward function is known and we only need to find a policy to maximize the reward function) and inverse reinforcement learning models (that is, wherein the reward function is unknown, and we have to learn the most reasonable reward function through the decision-making examples of clinicians) - 4 papers used typical reinforcement learning model, and 2 papers used inverse reinforcement learning models.

All 6 papers used patient data from the intensive care units in US hospitals. Most papers used single-center data from MIMIC II ( $\mathrm{n}=1)$ or MIMIC III ( $\mathrm{n}=4)$, with $c$ ranging from 707 to 96,156 (mean 22,256; median 7852).

Because the output of a reinforcement learning model is a policy that is not easy to evaluate, in these studies, the policy given by the model was compared with that actually given by the doctor; when the 2 policies differed, the effect of the reinforcement learning model was analyzed according to the actual clinical problem.

\section{Discussion}

From reviewed studies, we concluded that early identification of clinical outcome prediction and prognosis assessment contributed to approximately $80 \%$ of studies, and machine learning-based clinical decision support applications in intensive care unit could support timely bedside decision-making [15], transform data into more actionable insights or evidence-based clinical rules [101], assist disease diagnosis [30], predict adverse outcomes before they happen [76], enable continuous assessment of patient responses to critical care interventions [91], allow better management of highly complex situations and the best treatment decisions [3], ultimately reduce clinicians burden [52], and allow clinicians to have more time to deliver their knowledge, experience, and human care in practice [64].

We found that $91 \%$ (88/97) of reviewed studies used supervised learning methods. Unsupervised learning is commonly used for phenotyping or patient subgrouping [2], usually to discover new knowledge; therefore, explaining and validating subgroups or patterns with reasonable clinical meaning is a challenge. Reinforcement learning models have great potential for solving medical decision problems; however, to the best of our knowledge, there is a lack of sophisticated reinforcement learning models to guide intensive care unit decision-making [5]. Data-driven decision support tools will permit clinicians to function more efficiently, caring for more patients more safely; however the selection of a model should be tailored to the clinical scenario [9,10]; therefore, we need a better understanding of which algorithms are a best fit for which clinical scenarios.
We also found that many machine learning-based clinical prediction tasks are still challenging. First, not all the data collected from intensive care unit are good quality data or complete [7], particularly when data from different sources were included in one predictive model. Various data in the intensive care unit include general available data in the electronic health record, such as patient information, encounter information, diagnoses, intervention, routine laboratory data, imaging, natural language and physiologic data, as well as limited available information in the intensive care unit, such as social information, omics data, pathology, radiology, and wearable data [103]. This makes data preprocessing a difficult and time-consuming task. Second, parameter optimization was used to obtain the best parameter combination to improve model accuracy. Model parameters need to be determined and fitted using the training data set, and many adjustable hyperparameters must be tuned to obtain a model with optimal performance [104]. Generally, the more complex the model, the more parameters need to be adjusted, and the more difficult it is to adjust the parameters. For example, in logistic regression [74], usually only the regularization coefficient is adjusted; and in random forest models [53], the hyperparameters that need to be adjusted include the number of trees, the maximum depth of the tree, and the split criteria. Third, typically, the more complex the model, the higher the required sample size [105]. If the sample size is insufficient, overfitting occurs easily, which leads to instability or inaccuracy of the model. In some clinical scenarios, owing to the limited sample size, the use of complex models is limited [59]. Last, after developing the model, prospective evaluation using external data sets and clinical trials should be conducted before using the model in practice [106] to improve confidence in machine learning predictions [7]; however, performing strong validation of a machine learning model's generalizability and interpretability is challenging; internal validation approaches, such as cross-validation and bootstrapping, cannot guarantee the quality of a machine learning model due to potentially biased training data and the complexity of the validation procedure itself [107]. Lack of technical and semantic interoperability makes harmonization of patient data from one center to another costly. As inconsistent model results may be derived when adapting to new data sets [108], retraining models using data from other sources would minimize the cost and allow models to incorporate new clinical settings.

Future research should expand the innovation and exploration using new algorithms to solve intensive care unit clinical problems by developing reinforcement learning, active learning, and time-series analysis methods for clinical decision support. In addition, machine learning modeling requires recognition, understanding, and trust from intensive care unit clinicians. Model developers must provide full explanations of modeling methods, input, output, experimental and trial settings, clinical scenarios, and operation methods to clinicians. With the basis to understand, operate, and debug the outputs of a model, clinicians can have more confidence in accepting the model results and take action on the basis of that model's recommendations. 


\section{Acknowledgments}

This study was supported by the National Key Research and Development Program of China (2021YFC2500800) and Beijing Nova Program from Beijing Municipal Science and Technology Commission (Z201100006820126).

\section{Authors' Contributions}

LS and NH were responsible for study design and conception. NH and CL performed the search. NH, CL, JG, and LH were responsible for literature review and data analysis. NH, CL, JG, LH, MG and LS interpreted the results. FC supported data processing and analysis. All authors drafted and revised the manuscript for important intellectual content.

\section{Conflicts of Interest}

None declared.

\section{Multimedia Appendix 1}

Supplementary information.

[DOCX File , 65 KB-Multimedia Appendix 1]

\section{References}

1. Pierre L. An introduction to machine learning. Language Technology Group (LTG). 2015. URL: https://studylib.net/doc/ 11539838/an-introduction-to-machine-learning-pierre-lison--languag [accessed 2022-02-03]

2. Su L, Zhang Z, Zheng F, Pan P, Hong N, Liu C, et al. Five novel clinical phenotypes for critically ill patients with mechanical ventilation in intensive care units: a retrospective and multi database study. Respir Res 2020 Dec 10;21(1):325 [FREE Full text] [doi: 10.1186/s12931-020-01588-6] [Medline: 33302940]

3. Srinivasan S, Doshi-Velez F. Interpretable batch IRL to extract clinician goals in ICU hypotension management. AMIA Jt Summits Transl Sci Proc 2020;2020:636-645 [FREE Full text] [Medline: $\underline{32477686]}$

4. Yu C, Liu J, Zhao H. Inverse reinforcement learning for intelligent mechanical ventilation and sedative dosing in intensive care units. BMC Med Inform Decis Mak 2019 Apr 09;19(Suppl 2):57 [FREE Full text] [doi: 10.1186/s12911-019-0763-6] [Medline: 30961594]

5. Nemati S, Ghassemi MM, Clifford GD. Optimal medication dosing from suboptimal clinical examples: a deep reinforcement learning approach. Annu Int Conf IEEE Eng Med Biol Soc 2016 Aug;2016:2978-2981. [doi: 10.1109/EMBC.2016.7591355] [Medline: 28268938]

6. Yu C, Ren G, Dong Y. Supervised-actor-critic reinforcement learning for intelligent mechanical ventilation and sedative dosing in intensive care units. BMC Med Inform Decis Mak 2020 Jul 09;20(Suppl 3):124 [FREE Full text] [doi: 10.1186/s12911-020-1120-5] [Medline: 32646412]

7. Komorowski M, Celi LA, Badawi O, Gordon AC, Faisal AA. The Artificial Intelligence Clinician learns optimal treatment strategies for sepsis in intensive care. Nat Med 2018 Nov;24(11):1716-1720. [doi: 10.1038/s41591-018-0213-5] [Medline: $\underline{30349085]}$

8. Lopez-Martinez D, Eschenfeldt P, Ostvar S, Ingram M, Hur C, Picard R. Deep reinforcement learning for optimal critical care pain management with morphine using dueling double-deep Q networks. Annu Int Conf IEEE Eng Med Biol Soc 2019 Jul;2019:3960-3963. [doi: 10.1109/EMBC.2019.8857295] [Medline: 31946739]

9. Greco M, Caruso PF, Cecconi M. Artificial intelligence in the intensive care unit. Semin Respir Crit Care Med 2021 Feb;42(1):2-9. [doi: 10.1055/s-0040-1719037] [Medline: 33152770]

10. Hanson CW, Marshall BE. Artificial intelligence applications in the intensive care unit. Crit Care Med 2001 Feb;29(2):427-435. [doi: 10.1097/00003246-200102000-00038] [Medline: 11269246]

11. Rueckel J, Kunz WG, Hoppe BF, Patzig M, Notohamiprodjo M, Meinel FG, et al. Artificial intelligence algorithm detecting lung infection in supine chest radiographs of critically ill patients with a diagnostic accuracy similar to board-certified radiologists. Crit Care Med 2020 Jul;48(7):e574-e583. [doi: 10.1097/CCM.0000000000004397] [Medline: 32433121]

12. Eshelman LJ, Lee KP, Frassica JJ, Zong W, Nielsen L, Saeed M. Development and evaluation of predictive alerts for hemodynamic instability in ICU patients. AMIA Annu Symp Proc 2008 Nov 06:379-383 [FREE Full text] [Medline: $\underline{18999006]}$

13. Quinn JA, Williams CKI, McIntosh N. Factorial switching linear dynamical systems applied to physiological condition monitoring. IEEE Trans Pattern Anal Mach Intell 2009 Sep;31(9):1537-1551. [doi: 10.1109/TPAMI.2008.191] [Medline: 19574617]

14. Charbonnier S. On line extraction of temporal episodes from ICU high-frequency data: a visual support for signal interpretation. Comput Methods Programs Biomed 2005 May;78(2):115-132. [doi: 10.1016/j.cmpb.2005.01.003] [Medline: $\underline{15848267]}$ 
15. Zhang Y, Szolovits P. Patient-specific learning in real time for adaptive monitoring in critical care. J Biomed Inform 2008 Jun;41(3):452-460 [FREE Full text] [doi: 10.1016/j.jbi.2008.03.011] [Medline: 18463000 ]

16. Kwok HF, Linkens DA, Mahfouf M, Mills GH. Adaptive ventilator FiO2 advisor: use of non-invasive estimations of shunt. Artif Intell Med 2004 Nov;32(3):157-169. [doi: 10.1016/j.artmed.2004.02.005] [Medline: 15531148]

17. Rehm GB, Han J, Kuhn BT, Delplanque J, Anderson NR, Adams JY, et al. Creation of a robust and generalizable machine learning classifier for patient ventilator asynchrony. Methods Inf Med 2018 Sep;57(4):208-219. [doi: 10.3414/ME17-02-0012] [Medline: 30919393]

18. Gholami B, Phan TS, Haddad WM, Cason A, Mullis J, Price L, et al. Replicating human expertise of mechanical ventilation waveform analysis in detecting patient-ventilator cycling asynchrony using machine learning. Comput Biol Med 2018 Jun 01;97:137-144. [doi: 10.1016/j.compbiomed.2018.04.016] [Medline: 29729488]

19. Koolen N, Oberdorfer L, Rona Z, Giordano V, Werther T, Klebermass-Schrehof K, et al. Automated classification of neonatal sleep states using EEG. Clin Neurophysiol 2017 Jun;128(6):1100-1108. [doi: 10.1016/j.clinph.2017.02.025] [Medline: 28359652]

20. Farzaneh N, Williamson CA, Jiang C, Srinivasan A, Bapuraj JR, Gryak J, et al. Automated segmentation and severity analysis of subdural hematoma for patients with traumatic brain injuries. Diagnostics 2020;10(10):773 [FREE Full text] [doi: 10.3390/diagnostics10100773] [Medline: 33007929]

21. Golmohammadi M, Harati Nejad Torbati AH, Lopez de Diego S, Obeid I, Picone J. Automatic analysis of EEGs using big data and hybrid deep learning architectures. Front Hum Neurosci 2019;13:76 [FREE Full text] [doi: 10.3389/fnhum.2019.00076] [Medline: 30914936]

22. Sorani MD, Hemphill JC, Morabito D, Rosenthal G, Manley GT. New approaches to physiological informatics in neurocritical care. Neurocrit Care 2007;7(1):45-52. [doi: 10.1007/s12028-007-0043-7] [Medline: 17565451]

23. Calvert J, Desautels T, Chettipally U, Barton C, Hoffman J, Jay M, et al. High-performance detection and early prediction of septic shock for alcohol-use disorder patients. Ann Med Surg (Lond) 2016 Jun;8:50-55 [FREE Full text] [doi:

10.1016/j.amsu.2016.04.023] [Medline: 27489621]

24. Timsit J, Perner A. Sepsis: find me, manage me, and stop me!. Intensive Care Med 2016 Dec 24;42(12):1851-1853. [doi: 10.1007/s00134-016-4603-1] [Medline: 27778045]

25. Soliman IW, Frencken JF, Peelen LM, Slooter AJC, Cremer OL, van Delden JJ, et al. The predictive value of early acute kidney injury for long-term survival and quality of life of critically ill patients. Crit Care 2016 Aug 03;20(1):242 [FREE Full text] [doi: 10.1186/s13054-016-1416-0] [Medline: 27488839]

26. Sun M, Baron J, Dighe A, Szolovits P, Wunderink RG, Isakova T, et al. Early prediction of acute kidney injury in critical care setting using clinical notes and structured multivariate physiological measurements. Stud Health Technol Inform 2019 Aug 21;264:368-372. [doi: 10.3233/SHTI190245] [Medline: 31437947]

27. Sanchez-Pinto LN, Khemani RG. Development of a prediction model of early acute kidney injury in critically ill children using electronic health record data. Pediatr Crit Care Med 2016 Jun;17(6):508-515. [doi: 10.1097/PCC.0000000000000750] [Medline: 27124567]

28. Fadlalla AMA, Golob JF, Claridge JA. Enhancing the fever workup utilizing a multi-technique modeling approach to diagnose infections more accurately. Surg Infect (Larchmt) 2012 Apr;13(2):93-101 [FREE Full text] [doi: 10.1089/sur.2008.057] [Medline: 20666579]

29. Nemati S, Holder A, Razmi F, Stanley MD, Clifford GD, Buchman TG. An interpretable machine learning model for accurate prediction of sepsis in the ICU. Crit Care Med 2018 Apr;46(4):547-553. [doi: 10.1097/CCM.0000000000002936] [Medline: 29286945]

30. Kam HJ, Kim HY. Learning representations for the early detection of sepsis with deep neural networks. Comput Biol Med 2017 Dec 01;89:248-255. [doi: 10.1016/j.compbiomed.2017.08.015] [Medline: 28843829]

31. Kaji DA, Zech JR, Kim JS, Cho SK, Dangayach NS, Costa AB, et al. An attention based deep learning model of clinical events in the intensive care unit. PLoS One 2019;14(2):e0211057 [FREE Full text] [doi: 10.1371/journal.pone.0211057] [Medline: 30759094]

32. Scherpf M, Gräßer F, Malberg H, Zaunseder S. Predicting sepsis with a recurrent neural network using the MIMIC III database. Comput Biol Med 2019 Oct;113:103395. [doi: 10.1016/j.compbiomed.2019.103395] [Medline: 31480008 ]

33. Wang S, Wu F, Wang B. Prediction of severe sepsis using SVM model. Adv Exp Med Biol 2010;680:75-81. [doi: 10.1007/978-1-4419-5913-3 9] [Medline: 20865488]

34. Desautels T, Calvert J, Hoffman J, Jay M, Kerem Y, Shieh L, et al. Prediction of sepsis in the intensive care unit with minimal electronic health record data: a machine learning approach. JMIR Med Inform 2016 Sep 30;4(3):e28 [FREE Full text] [doi: 10.2196/medinform.5909] [Medline: 27694098]

35. Mao Q, Jay M, Hoffman JL, Calvert J, Barton C, Shimabukuro D, et al. Multicentre validation of a sepsis prediction algorithm using only vital sign data in the emergency department, general ward and ICU. BMJ Open 2018 Jan 26;8(1):e017833 [FREE Full text] [doi: 10.1136/bmjopen-2017-017833] [Medline: 29374661]

36. Metsvaht T, Pisarev H, Ilmoja M, Parm U, Maipuu L, Merila M, et al. Clinical parameters predicting failure of empirical antibacterial therapy in early onset neonatal sepsis, identified by classification and regression tree analysis. BMC Pediatr 2009 Nov 24;9:72 [FREE Full text] [doi: 10.1186/1471-2431-9-72] [Medline: 19930706] 
37. Mani S, Ozdas A, Aliferis C, Varol HA, Chen Q, Carnevale R, et al. Medical decision support using machine learning for early detection of late-onset neonatal sepsis. J Am Med Inform Assoc 2014 Mar;21(2):326-336 [FREE Full text] [doi: 10.1136/amiajnl-2013-001854] [Medline: 24043317]

38. Shahin J, Allen EJ, Patel K, Muskett H, Harvey SE, Edgeworth J, FIRE Study Investigators. Predicting invasive fungal disease due to Candida species in non-neutropenic, critically ill, adult patients in United Kingdom critical care units. BMC Infect Dis 2016 Sep 09;16:480 [FREE Full text] [doi: 10.1186/s12879-016-1803-9] [Medline: 27612566]

39. Messinger AI, Bui N, Wagner BD, Szefler SJ, Vu T, Deterding RR. Novel pediatric-automated respiratory score using physiologic data and machine learning in asthma. Pediatr Pulmonol 2019 Aug;54(8):1149-1155 [FREE Full text] [doi: 10.1002/ppul.24342] [Medline: $\underline{31006993}$ ]

40. Sauthier MS, Jouvet PA, Newhams MM, Randolph AG. Machine learning predicts prolonged acute hypoxemic respiratory failure in pediatric severe influenza. Crit Care Explor 2020 Aug;2(8):e0175 [FREE Full text] [doi:

10.1097/CCE.0000000000000175] [Medline: 32832912]

41. Le S, Pellegrini E, Green-Saxena A, Summers C, Hoffman J, Calvert J, et al. Supervised machine learning for the early prediction of acute respiratory distress syndrome (ARDS). J Crit Care 2020 Dec;60:96-102 [FREE Full text] [doi: 10.1016/j.jcrc.2020.07.019] [Medline: $\underline{\text { 32777759] }}$

42. Hsu J, Chen Y, Chung W, Tan T, Chen T, Chiang JY. Clinical verification of a clinical decision support system for ventilator weaning. Biomed Eng Online 2013;12 Suppl 1:S4 [FREE Full text] [doi: 10.1186/1475-925X-12-S1-S4] [Medline: 24565021]

43. Miu T, Joffe AM, Yanez ND, Khandelwal N, Dagal AH, Deem S, et al. Predictors of reintubation in critically ill patients. Respir Care 2014 Feb;59(2):178-185 [FREE Full text] [doi: 10.4187/respcare.02527] [Medline: 23882103]

44. Isbister GK, Duffull SB. Quetiapine overdose: predicting intubation, duration of ventilation, cardiac monitoring and the effect of activated charcoal. Int Clin Psychopharmacol 2009 Jul;24(4):174-180. [doi: 10.1097/YIC.0b013e32832bb078] [Medline: 19494786 ]

45. Ghazal S, Sauthier M, Brossier D, Bouachir W, Jouvet PA, Noumeir R. Using machine learning models to predict oxygen saturation following ventilator support adjustment in critically ill children: A single center pilot study. PLoS One 2019;14(2):e0198921 [FREE Full text] [doi: 10.1371/journal.pone.0198921] [Medline: 30785881]

46. Rodríguez A, Ferri C, Martin-Loeches I, Díaz E, Masclans JR, Gordo F, Grupo Español de Trabajo Gripe A Grave (GETGAG)/Sociedad Española de Medicina Intensiva, Crítica y Unidades Coronarias (SEMICYUC) Working Group, 2009-2015 H1N1 SEMICYUC Working Group investigators. Risk factors for noninvasive ventilation failure in critically ill subjects with confirmed influenza infection. Respir Care 2017 Oct 11;62(10):1307-1315 [FREE Full text] [doi: 10.4187/respcare.05481] [Medline: 28698265]

47. Lin P, Huang H, Komorowski M, Lin W, Chang C, Chen K, et al. A machine learning approach for predicting urine output after fluid administration. Comput Methods Programs Biomed 2019 Aug;177:155-159. [doi: 10.1016/j.cmpb.2019.05.009] [Medline: $\underline{31319943}$ ]

48. Pappada SM, Owais MH, Cameron BD, Jaume JC, Mavarez-Martinez A, Tripathi RS, et al. An artificial neural network-based predictive model to support optimization of inpatient glycemic control. Diabetes Technol Ther 2020 May;22(5):383-394. [doi: 10.1089/dia.2019.0252] [Medline: $\underline{31687844]}$

49. Mamandipoor B, Majd M, Moz M, Osmani V. Blood lactate concentration prediction in critical care. Stud Health Technol Inform 2020 Jun 16;270:73-77. [doi: 10.3233/SHTI200125] [Medline: 32570349]

50. Su L, Liu C, Li D, He J, Zheng F, Jiang H, et al. Toward optimal heparin dosing by comparing multiple machine learning methods: retrospective study. JMIR Med Inform 2020 Jun 22;8(6):e17648 [FREE Full text] [doi: 10.2196/17648] [Medline: $\underline{32568089]}$

51. Yu L, Zhang Q, Bernstam EV, Jiang X. Predict or draw blood: an integrated method to reduce lab tests. J Biomed Inform 2020 Apr;104:103394. [doi: 10.1016/j.jbi.2020.103394] [Medline: 32113004]

52. Cismondi F, Celi LA, Fialho AS, Vieira SM, Reti SR, Sousa JMC, et al. Reducing unnecessary lab testing in the ICU with artificial intelligence. Int J Med Inform 2013 May;82(5):345-358 [FREE Full text] [doi: 10.1016/j.ijmedinf.2012.11.017] [Medline: 23273628]

53. Li K, Wu H, Pan F, Chen L, Feng C, Liu Y, et al. A machine learning-based model to predict acute traumatic coagulopathy in trauma patients upon emergency hospitalization. Clin Appl Thromb Hemost 2020;26:1076029619897827 [FREE Full text] [doi: 10.1177/1076029619897827] [Medline: $\underline{\text { 31908189] }}$

54. Oh S, Park E, Jin Y, Piao J, Lee S. Automatic delirium prediction system in a Korean surgical intensive care unit. Nurs Crit Care 2014 Nov;19(6):281-291. [doi: 10.1111/nicc.12048] [Medline: 24165109]

55. Milbrandt EB, Clermont G, Martinez J, Kersten A, Rahim MT, Angus DC. Predicting late anemia in critical illness. Crit Care 2006 Feb;10(1):R39 [FREE Full text] [doi: 10.1186/cc4847] [Medline: 16507173]

56. Fialho AS, Celi LA, Cismondi F, Vieira SM, Reti SR, Sousa JMC, et al. Disease-based modeling to predict fluid response in intensive care units. Methods Inf Med 2013;52(6):494-502 [FREE Full text] [doi: 10.3414/ME12-01-0093] [Medline: 23986268]

57. Ghose S, Mitra J, Khanna S, Dowling J. An improved patient-specific mortality risk prediction in ICU in a random forest classification framework. Stud Health Technol Inform 2015;214:56-61. [Medline: 26210418] 
58. Venugopalan J, Chanani N, Maher K, Wang MD. Combination of static and temporal data analysis to predict mortality and readmission in the intensive care. Annu Int Conf IEEE Eng Med Biol Soc 2017 Jul;2017:2570-2573 [FREE Full text] [doi: 10.1109/EMBC.2017.8037382] [Medline: 29060424]

59. Ting H, Chen M, Hsieh Y, Chan C. Good mortality prediction by Glasgow Coma Scale for neurosurgical patients. J Chin Med Assoc 2010 Mar;73(3):139-143 [FREE Full text] [doi: 10.1016/S1726-4901(10)70028-9] [Medline: 20230998]

60. Sha Y, Wang MD. Interpretable predictions of clinical outcomes with an attention-based recurrent neural network. ACM BCB 2017 Aug;2017:233-240 [FREE Full text] [doi: 10.1145/3107411.3107445] [Medline: 32577628]

61. Meiring C, Dixit A, Harris S, MacCallum NS, Brealey DA, Watkinson PJ, et al. Optimal intensive care outcome prediction over time using machine learning. PLoS One 2018;13(11):e0206862. [doi: 10.1371/journal.pone.0206862] [Medline: 30427913]

62. Bukan RI, Møller AM, Henning MAS, Mortensen KB, Klausen TW, Waldau T. Preadmission quality of life can predict mortality in intensive care unit--a prospective cohort study. J Crit Care 2014 Dec;29(6):942-947. [doi: 10.1016/j.jcrc.2014.06.009] [Medline: 25060638]

63. Hsieh Y, Su M, Wang C, Wang P. Prediction of survival of ICU patients using computational intelligence. Comput Biol Med 2014 Apr;47:13-19. [doi: 10.1016/j.compbiomed.2013.12.012] [Medline: 24508564]

64. Oeyen S, Vermeulen K, Benoit D, Annemans L, Decruyenaere J. Development of a prediction model for long-term quality of life in critically ill patients. J Crit Care 2018 Feb;43:133-138. [doi: 10.1016/j.jcrc.2017.09.006] [Medline: 28892669]

65. de Lange DW, Brinkman S, Flaatten H, Boumendil A, Morandi A, Andersen FH, VIP1 Study Group. Cumulative prognostic score predicting mortality in patients older than 80 years admitted to the ICU. J Am Geriatr Soc 2019 Jun;67(6):1263-1267 [FREE Full text] [doi: 10.1111/igs.15888] [Medline: $\underline{\text { 30977911] }}$

66. Guidet B, de Lange DW, Boumendil A, Leaver S, Watson X, Boulanger C, VIP2 study group. The contribution of frailty, cognition, activity of daily life and comorbidities on outcome in acutely admitted patients over 80 years in European ICUs: the VIP2 study. Intensive Care Med 2020 Jan;46(1):57-69 [FREE Full text] [doi: 10.1007/s00134-019-05853-1] [Medline: $\underline{31784798}]$

67. Heyland DK, Stelfox HT, Garland A, Cook D, Dodek P, Kutsogiannis J, Canadian Critical Care Trials Group and the Canadian Researchers at the End of Life Network. Predicting performance status 1 year after critical illness in patients 80 years or older: development of a multivariable clinical prediction model. Crit Care Med 2016 Sep;44(9):1718-1726. [doi: 10.1097/CCM.0000000000001762] [Medline: 27075141]

68. Puskarich M. A decision tree incorporating biomarkers and patient characteristics estimates mortality risk for adults with septic shock. Evid Based Nurs 2015 Apr;18(2):42. [doi: 10.1136/eb-2014-101903] [Medline: 25163470]

69. Wong HR, Lindsell CJ, Pettilä V, Meyer NJ, Thair SA, Karlsson S, et al. A multibiomarker-based outcome risk stratification model for adult septic shock*. Crit Care Med 2014 Apr;42(4):781-789 [FREE Full text] [doi: 10.1097/CCM.0000000000000106] [Medline: 24335447]

70. Jaimes F, Farbiarz J, Alvarez D, Martínez C. Comparison between logistic regression and neural networks to predict death in patients with suspected sepsis in the emergency room. Crit Care 2005 Apr;9(2):R150-R156 [FREE Full text] [doi: 10.1186/cc3054] [Medline: 15774048]

71. Ribas Ripoll VJ, Vellido A, Romero E, Ruiz-Rodríguez JC. Sepsis mortality prediction with the Quotient Basis Kernel. Artif Intell Med 2014 May;61(1):45-52. [doi: 10.1016/j.artmed.2014.03.004] [Medline: 24726036]

72. Sha Y, Venugopalan J, Wang MD. A novel temporal similarity measure for patients based on irregularly measured data in electronic health records. ACM BCB 2016 Oct;2016:337-344 [FREE Full text] [doi: 10.1145/2975167.2975202] [Medline: 32577627]

73. Yang T, Sun S, Zhao Y, Liu Q, Han M, Lin L, et al. Biomarkers upon discontinuation of renal replacement therapy predict 60-day survival and renal recovery in critically ill patients with acute kidney injury. Hemodial Int 2018 Jan;22(1):56-65. [doi: 10.1111/hdi.12532] [Medline: 28078828]

74. Xu Z, Luo Y, Adekkanattu P, Ancker JS, Jiang G, Kiefer RC, et al. Stratified mortality prediction of patients with acute kidney injury in critical care. Stud Health Technol Inform 2019 Aug 21;264:462-466. [doi: 10.3233/SHTI190264] [Medline: 31437966]

75. Trongtrakul K, Patumanond J, Kongsayreepong S, Morakul S, Pipanmekaporn T, Akaraborworn O, et al. Acute kidney injury risk prediction score for critically-ill surgical patients. BMC Anesthesiol 2020 Jun 03;20(1):140 [FREE Full text] [doi: 10.1186/s12871-020-01046-2] [Medline: 32493268]

76. Bernal W, Wang Y, Maggs J, Willars C, Sizer E, Auzinger G, et al. Development and validation of a dynamic outcome prediction model for paracetamol-induced acute liver failure: a cohort study. Lancet Gastroenterol Hepatol 2016 Nov;1(3):217-225. [doi: 10.1016/S2468-1253(16)30007-3] [Medline: 28404094]

77. Lindenmeyer CC, Flocco G, Sanghi V, Lopez R, Kim AJ, Niyazi F, et al. LIV-4: A novel model for predicting transplant-free survival in critically ill cirrhotics. World J Hepatol 2020 Jun 27;12(6):298-311 [FREE Full text] [doi: 10.4254/wjh.v12.i6.298] [Medline: 32742572]

78. Balekian AA, Gould MK. Predicting in-hospital mortality among critically ill patients with end-stage liver disease. J Crit Care 2012 Dec;27(6):740.e1-740.e7 [FREE Full text] [doi: 10.1016/j.jcrc.2012.08.017] [Medline: 23059012] 
79. Santos HGD, Zampieri FG, Normilio-Silva K, Silva GTD, Lima ACPD, Cavalcanti AB, et al. Machine learning to predict 30-day quality-adjusted survival in critically ill patients with cancer. J Crit Care 2020 Feb;55:73-78. [doi: 10.1016/j.jcrc.2019.10.015] [Medline: 31715534$]$

80. Vincent F, Soares M, Mokart D, Lemiale V, Bruneel F, Boubaya M, GrrrOH: Groupe de recherche respiratoire en réanimation en Onco-Hématologie (Group for respiratory research in intensive care in Onco-Hematology, http://www.grrroh.com/). In-hospital and day-120 survival of critically ill solid cancer patients after discharge of the intensive care units: results of a retrospective multicenter study-A Groupe de recherche respiratoire en réanimation en Onco-Hématologie $(\mathrm{Grrr}-\mathrm{OH})$ study. Ann Intensive Care 2018 Mar 27;8(1):40 [FREE Full text] [doi: 10.1186/s13613-018-0386-6] [Medline: 29582210]

81. Lee S, Zhao X, Davis KA, Topjian AA, Litt B, Abend NS. Quantitative EEG predicts outcomes in children after cardiac arrest. Neurology 2019 May 14;92(20):e2329-e2338 [FREE Full text] [doi: 10.1212/WNL.0000000000007504] [Medline: 30971485]

82. Murtuza B, Wall D, Reinhardt Z, Stickley J, Stumper O, Jones TJ, et al. The importance of blood lactate clearance as a predictor of early mortality following the modified Norwood procedure. Eur J Cardiothorac Surg 2011 Nov;40(5):1207-1214. [doi: 10.1016/j.ejcts.2011.01.081] [Medline: 21450476]

83. Gracia Arnillas MP, Alvarez-Lerma F, Masclans J, Roquer J, Soriano C, Manzano D, et al. Impact of adrenomedullin levels on clinical risk stratification and outcome in subarachnoid haemorrhage. Eur J Clin Invest 2020 Nov;50(11):e13318. [doi: 10.1111/eci.13318] [Medline: 32535893]

84. Haveman ME, Van Putten MJAM, Hom HW, Eertman-Meyer CJ, Beishuizen A, Tjepkema-Cloostermans MC. Predicting outcome in patients with moderate to severe traumatic brain injury using electroencephalography. Crit Care 2019 Dec 11;23(1):401 [FREE Full text] [doi: 10.1186/s13054-019-2656-6] [Medline: 31829226]

85. Wildman MJ, Sanderson C, Groves J, Reeves BC, Ayres J, Harrison D, et al. Predicting mortality for patients with exacerbations of COPD and asthma in the COPD and asthma outcome study (CAOS). QJM 2009 Jun;102(6):389-399. [doi: 10.1093/qjmed/hcp036] [Medline: 19369483]

86. Daly K, Beale R, Chang RW. Reduction in mortality after inappropriate early discharge from intensive care unit: logistic regression triage model. BMJ 2001 May 26;322(7297):1274-1276 [FREE Full text] [doi: 10.1136/bmj.322.7297.1274] [Medline: 11375229 ]

87. Hernández-Tejedor A, Cabré-Pericas L, Martín-Delgado MC, Leal-Micharet AM, Algora-Weber A, EPIPUSE study group. Evolution and prognosis of long intensive care unit stay patients suffering a deterioration: a multicenter study. J Crit Care 2015 Jun;30(3):654.e1-654.e7. [doi: 10.1016/j.jcrc.2015.01.011] [Medline: 25656920]

88. Ji S, Smith R, Huynh T, Najarian K. A comparative analysis of multi-level computer-assisted decision making systems for traumatic injuries. BMC Med Inform Decis Mak 2009 Jan 14;9:2 [FREE Full text] [doi: 10.1186/1472-6947-9-2] [Medline: 19144188]

89. Che Z, Purushotham S, Khemani R, Liu Y. Interpretable deep models for ICU outcome prediction. AMIA Annu Symp Proc 2016;2016:371-380 [FREE Full text] [Medline: 28269832]

90. Ebadollahi S, Sun J, Gotz D, Hu J, Sow D, Neti C. Predicting patient's trajectory of physiological data using temporal trends in similar patients: a system for near-term prognostics. AMIA Annu Symp Proc 2010 Nov 13;2010:192-196 [FREE Full text] [Medline: 21346967]

91. Castiñeira D, Schlosser KR, Geva A, Rahmani AR, Fiore G, Walsh BK, et al. Adding continuous vital sign information to static clinical data improves the prediction of length of stay after intubation: a data-driven machine learning approach. Respir Care 2020 Sep;65(9):1367-1377. [doi: 10.4187/respcare.07561] [Medline: 32879034]

92. Mueller M, Wagner CL, Annibale DJ, Knapp RG, Hulsey TC, Almeida JS. Parameter selection for and implementation of a web-based decision-support tool to predict extubation outcome in premature infants. BMC Med Inform Decis Mak 2006 Mar 01;6:11 [FREE Full text] [doi: 10.1186/1472-6947-6-11] [Medline: 16509967]

93. Mueller M, Wagner CL, Annibale DJ, Hulsey TC, Knapp RG, Almeida JS. Predicting extubation outcome in preterm newborns: a comparison of neural networks with clinical expertise and statistical modeling. Pediatr Res 2004 Jul;56(1):11-18. [doi: 10.1203/01.PDR.0000129658.55746.3C] [Medline: 15128922]

94. Dunning J, Au J, Kalkat M, Levine A. A validated rule for predicting patients who require prolonged ventilation post cardiac surgery. Eur J Cardiothorac Surg 2003 Aug;24(2):270-276. [doi: 10.1016/s1010-7940(03)00269-0] [Medline: 12895619]

95. Manji RA, Arora RC, Singal RK, Hiebert B, Moon MC, Freed DH, et al. Long-term outcome and predictors of noninstitutionalized survival subsequent to prolonged intensive care unit stay after cardiac surgical procedures. Ann Thorac Surg 2016 Jan;101(1):56-63; discussion 63. [doi: 10.1016/j.athoracsur.2015.07.004] [Medline: 26431924]

96. Brandi S, Troster EJ, Cunha MLDR. Length of stay in pediatric intensive care unit: prediction model. Einstein (Sao Paulo) 2020;18:eAO5476 [FREE Full text] [doi: 10.31744/einstein journal/2020AO5476] [Medline: 33053018]

97. McWilliams CJ, Lawson DJ, Santos-Rodriguez R, Gilchrist ID, Champneys A, Gould TH, et al. Towards a decision support tool for intensive care discharge: machine learning algorithm development using electronic healthcare data from MIMIC-III and Bristol, UK. BMJ Open 2019 Mar 07;9(3):e025925 [FREE Full text] [doi: 10.1136/bmjopen-2018-025925] [Medline: $\underline{30850412]}$ 
98. Lin Y, Zhou Y, Faghri F, Shaw MJ, Campbell RH. Analysis and prediction of unplanned intensive care unit readmission using recurrent neural networks with long short-term memory. PLoS One 2019;14(7):e0218942 [FREE Full text] [doi: 10.1371/journal.pone.0218942] [Medline: $\underline{\text { 31283759] }}$

99. Czeiter E, Amrein K, Gravesteijn BY, Lecky F, Menon DK, Mondello S, CENTER-TBI Participants and Investigators. Blood biomarkers on admission in acute traumatic brain injury: relations to severity, CT findings and care path in the CENTER-TBI study. EBioMedicine 2020 Jun;56:102785 [FREE Full text] [doi: 10.1016/j.ebiom.2020.102785] [Medline: 32464528]

100. Yin W, Li Y, Zeng X, Qin Y, Wang D, Zou T, et al. The utilization of critical care ultrasound to assess hemodynamics and lung pathology on ICU admission and the potential for predicting outcome. PLoS One 2017;12(8):e0182881 [FREE Full text] [doi: 10.1371/journal.pone.0182881] [Medline: 28806783]

101. Shickel B, Loftus TJ, Adhikari L, Ozrazgat-Baslanti T, Bihorac A, Rashidi P. DeepSOFA: a continuous acuity score for critically ill patients using clinically interpretable deep learning. Sci Rep 2019 Feb 12;9(1):1879 [FREE Full text] [doi: 10.1038/s41598-019-38491-0] [Medline: 30755689]

102. McRae MP, Simmons GW, Christodoulides NJ, Lu Z, Kang SK, Fenyo D, et al. Clinical decision support tool and rapid point-of-care platform for determining disease severity in patients with COVID-19. Lab Chip 2020 Jun 21;20(12):2075-2085. [doi: 10.1039/d0lc00373e] [Medline: 32490853]

103. Sanchez-Pinto LN, Luo Y, Churpek MM. Big data and data science in critical care. Chest 2018 Nov;154(5):1239-1248. [doi: 10.1016/j.chest.2018.04.037]

104. Liu Y, Chen PHC, Krause J, Peng L. How to read articles that use machine learning: users' guides to the medical literature. JAMA 2019 Nov 12;322(18):1806-1816. [doi: 10.1001/jama.2019.16489] [Medline: $\underline{31714992]}$

105. Riley RD, Ensor J, Snell KIE, Harrell FE, Martin GP, Reitsma JB, et al. Calculating the sample size required for developing a clinical prediction model. BMJ 2020 Mar 18;368:m441. [doi: 10.1136/bmj.m441] [Medline: 32188600$]$

106. Collins GS, Reitsma JB, Altman DG, Moons KGM. Transparent reporting of a multivariable prediction model for individual prognosis or diagnosis (TRIPOD): the TRIPOD statement. Br J Surg 2015 Feb;102(3):148-158. [doi: 10.1002/bjs.9736] [Medline: 25627261]

107. Ho SY, Phua K, Wong L, Bin Goh WW. Extensions of the external validation for checking learned model interpretability and generalizability. Patterns 2020 Nov;1(8):100129. [doi: 10.1016/j.patter.2020.100129]

108. Futoma J, Simons M, Panch T, Doshi-Velez F, Celi LA. The myth of generalisability in clinical research and machine learning in health care. Lancet Digit Health 2020 Sep;2(9):e489-e492 [FREE Full text] [doi: 10.1016/S2589-7500(20)30186-2] [Medline: $\underline{\text { 32864600] }}$

\title{
Abbreviations
}

EEG: electroencephalography

\author{
Edited by A Mavragani; submitted 15.03.21; peer-reviewed by J Wang, MC Lin, Y Wang, J Li; comments to author 12.04.21; revised \\ version received 02.07.21; accepted 01.12.21; published 03.03.22 \\ Please cite as: \\ Hong N, Liu C, Gao J, Han L, Chang F, Gong M, Su L \\ State of the Art of Machine Learning-Enabled Clinical Decision Support in Intensive Care Units: Literature Review \\ JMIR Med Inform 2022;10(3):e28781 \\ URL: https://medinform.jmir.org/2022/3/e28781 \\ doi: $10.2196 / 28781$ \\ PMID:
}

CNa Hong, Chun Liu, Jianwei Gao, Lin Han, Fengxiang Chang, Mengchun Gong, Longxiang Su. Originally published in JMIR Medical Informatics (https://medinform.jmir.org), 03.03.2022. This is an open-access article distributed under the terms of the Creative Commons Attribution License (https://creativecommons.org/licenses/by/4.0/), which permits unrestricted use, distribution, and reproduction in any medium, provided the original work, first published in JMIR Medical Informatics, is properly cited. The complete bibliographic information, a link to the original publication on https://medinform.jmir.org/, as well as this copyright and license information must be included. 